\title{
EXPLORING THE CULTURE WAR: A JOURNEY WITH TIM MILLER
}

\section{Darrell Taylor}

Tim Miller is a Los Angeles-based performance artist, writer, teacher, and gay activist. Miller is possibly best known as one of the famed NEA Four who, along with Holly Hughes, John Fleck, and Karen Finley, successfully sued the federal government for violating his First Amendment rights. What such notoriety does not impart to the average art or news enthusiast is this artist's great charm, generosity, altruism, and humor. The following is an interview conducted on October 5, 1997, while driving to Chicago on the first leg of a nationwide book tour. Our conversation ranged from the function of the performance artist to queer representation and validation as well as First Amendment issues, activism, nudity, desire, and the body.

Do you see yourself as sort of an avatar in the performance space?

We like to imagine that art does not have a social function, that it does not serve as a change agent for social issues. I believe that it does. I believe that it clearly has a healing function. A lot of the time, especially in intellectual circles, people are more ready to talk about social activism and not so much about inner work or personal transformation, and I think that's partly why people come here [to the performance space]. Through the performer, they are able to go on their own journey, and in that sense you become a kind of avatar carrying them along.

What is the performative function of "the journey?" What is the intellectual and emotional function of "the journey?"

In most journeys, whether they are spiritual initiations or political transformations, you set up a situation and then there's a descent of some kind, which is certainly true in my work. That's where the drama is. In the show this weekend [Fruit Cocktail at CSPS, a performance space and gallery in Cedar Rapids, IA] the descent is into a complex hallucination of the future.

As I see it, My Queer Body's performative function was the "outing” of the 
same-sex sexual encounter, enacting it and, therefore, creating space for it in the public arena.

Sexual and emotional intimacy are the topics I'm most interested in, partly because I think we do need representations that are humorous, intense, sexy. My Queer Body is definitely very big, heroic, and on a scale usually reserved for the heterosexual archetype. In fact, it subsumes the ultimate cliché heterosexual musical work, [Ravel's] Bolero, for homosexual ends. I think audiences need to hear that.

I like the fact that you used Handel's Messiah in Fruit Cocktail because it also exists in that realm of heterosexual privilege and representation.

Well, I like playing with music-it's powerful. [These pieces] are big cultural documents, but they're also theatrical and they play well. It's become a bit of a habit with me. I won't, however, let myself do The 1812 Overture.

You were one of the people Jesse Helms targeted over NEA funding several years ago. It seemed pretty clear at the time that the aim was to stifle homoerotic content, issues of bodily function, and commentary on religious conventions; however, the outcome was far more insidious. How would you characterize a government that seeks to frame creative expression?

I'm a First Amendment absolutist, including defending speech and art that I find hideous, racist, or what have you. You're either into the First Amendment or you're not. Obviously, I think it's very problematic inserting any kind of control over artistic content. I feel that very strongly. Clearly, the attacks were focused on lesbian and gay [material], and, as you say, on the body and bodily function. The culture war is ultimately a war about the body, I think. Lesbians, gays, transsexuals, and anyone talking about gender tend to be the stand-ins for the problematized body. It's much harder to attack heterosexual representations because they're so encoded in culture, whereas lesbian and gay representations are not. It's a short history, so it becomes a prime target.

How do you feel about federal arts monies being distributed from individual states, which is a real possibility in the near future?

Well, most state arts councils are much more conservative than the NEA in the old days. Also, a lot of state arts councils have no fellowship programs, so I actually feel better about money being in Washington. I think it's much more likely that an interesting artist in Oklahoma is going to get money from the NEA than from the Oklahoma Arts whatever, which is going to go for purely regional and extremely safe [material]. I think it's their strategy to continue sanitizing what's getting funded. As a strategy to save the federal agency -though it's probably not a bad one - but I'm not too optimistic about what kind of work is going to get supported.

Would you say that the publication of your new book, Shirts and Skin, signals a new direction in your creative career? Is this the beginning of a new stress on 
text and less reliance on performance, movement, and the engaging of space?

Younger artists around Highways [Tim's performance space in Santa Monica, $\mathrm{CA}$ ] are not nearly so monologue-oriented, they're really interested in space and non-theatrical time. I'm kind of glad, it's a big relief - we have enough monologues. For me, though, it's been a journey of claiming my words and seeing myself as a writer and storyteller, and this book is the biggest manifestation of that. Also, I'm getting older and... [We pass a marker on the road] Ooh! The birthplace of President Ronald Reagan. Ah! (Laughs.)

That's ironic, isn't it?

That's funny! (Laughs.) Since my work has been about my body, its memories and practices, I still hope to and will continue to [do work involving nakedness]. Like a lot of performers, I sometimes thought I wouldn't be capable of writing a book, that I couldn't participate in that way. It's been very empowering to actually have this book of stories I've written, so it's a direction I really want to keep exploring.

You often reveal stage conventions during performance, calling attention to the ritual origins of theatre, by exposing its "constructedness." How have you attempted this on the written page?

Mostly in a conventional way by drawing attention to writing [itself], goofing on my own metaphorical universe, goofing on my own writerliness at times. Some of it is shtick. Revealing your tricks is always fun, but it also reminds people they are witnessing an act of writing, this culturally constructed thing. It's refreshing for the reader to see the page differently, to indicate that you [the writer] have a meta-awareness about your objectives.

Shirts and Skin allows you to have a rather large and diverse audience. Was the intention to connect with more people than you are normally able to reach in a performance setting?

There's something very frustrating in knowing that the only way some people will ever get an idea of what I've been doing is by seeing me perform. I only [perform] at certain places every few years. I feel strongly that the book is a very good expression of my energy and my point of view, certainly the narratives and a lot of the issues that have been important to me. Obviously, you do lose "me" as a kind of embodied object for those avatar-like projections, but I think you gain some other things that I really like.

The dominant mythology says that performance works are inherently ephemeral, whereas books are tangible objects. Basically, one can pick up a book at any time.

Oh, yeah. I like that the stories I've been telling in my performances exist in a way - they've got good roots and can have a life now separate from the performances. I find it a big comfort. People who have never seen me before are 
reading the book. I like that a lot.

Though you often present your naked body in performance, I am not able to "see" you as naked for long in any given performance. I'm probably projecting this opinion, but I think you "dress" your body with stories, emotion, spirit.

Ah! Well, I keep communicating in the way most people are comfortable communicating, through language. I've been naked so much in performance-I enjoy it - and it never occurs to me that anything strange is happening. In a recent show with Alistaire [Tim's boyfriend], we do a long naked piece in which I'm whipped by my father for setting fire to our garage. While I'm telling the story I'm burning a lot of my body hair-pubic hair and arm hair. (You can't do a long run with that show.) Nakedness is not the main concern, it's the fear of my body being burned or setting myself on fire. It's what you do when you're naked. I usually indulge some humor which disarms people, but I don't always see my body as a site of humor because I also get quite serious and intense. I see my naked body as sexual and a [site] of pleasure. So, I often hear from people that my nakedness is integrated into the story, into the language. Words comfort people and allow them to relax. Some people say, "Oh, Why do you still need to be doing this naked stuff?" Americans are so fucked up about body and public nudity! So, I feel that this is a [topic] on which a lot of work will have to be done for a long time to come.

You have called your work "identity-based performance" as opposed to biography. How do you respond to those who insist that this type of work is selfindulgent, narcissistic?

They should be killed. (Laughs.) They should be brought before me, before my throne! But seriously, if I might reference my one academic essay, with professor David Román called "Preaching to the Converted," self-indulgent and preaching to the choir are classic [phrases] to dismiss the work of women, artists of color, and lesbian and gay men. It's the idea that an autobiographical story is self-indulgent somehow and a Jackson Pollock painting is not. I feel that all art is this wonderful complex act of ego, will, and indulging self that allows images and metaphors to come forward.

In the current issue of Vanity Fair there's a really nasty article about the dominant trend in writing: writing programs, creative non-fiction, etc. It's really mean-spirited. I think that the exploration by feminist artists a n d personal material has probably created more new space for artistic expression than anything since pure formal exploration. I don't think that the work is anywhere near done. Besides, usually the person calling something self-indulgent has some difficulties dealing with the story represented. There are a lot more interesting ways to criticize a work; for example, its metaphorical system is meager, its execution of language is [lifted]. Calling something self-indulgent is too easy.

You've appropriated "witnessing" and "testimony," a fundamentalist Protestant practice, in your work. Can you elaborate on that concept? 
American performance artists, almost across the board, are strongly influenced by preaching. American preaching, the most dramatic of which is AfricanAmerican preaching, [has had] a huge influence on American speech. We talk differently and express ourselves with a level of emphasis that is quite peculiar to English-speaking peoples. You simply don't hear people in Canada, Australia, or the U.K. talking like this. It's a rich, rich tradition and woven into most of the arts in this country. It's [also characterized by] single-mindedness, messianic vision, obsession. For the last number of years I've been interested in acknowledging the shamanic function of my work; consequently, I have worked in conventional religious settings as well.

You worked with Malcolm Boyd, an Episcopal priest in Santa Monica, in a series of "performance art sermons" in the early 1990s. Has that collaboration ended? Do you still wish to address that particular audience?

It was very, very important work for me to be engaged in a Protestant liturgy, the fundamental ritual that theatre is based upon, at a time when I was also feeling quite wounded from all the attacks from the Christian religious right. It was very [valuable] to be connecting with progressive Christians. I think that if progressive Christians in this country ever actually articulated their views in a useful way it could be a very powerful social movement like the Civil Rights Movement and the Anti-War Movement. The only time that any really effective mass social change happened in this country it was wed to the main structure of culture, religion; so, I feel it's good for people to relate to their cultural/religious upbringing.

At a certain point [the performance art sermons] began to interest me less; the form is limited. Also, that's not my church. Malcolm and I are very close, but I don't imagine we'll do it again. I would rather continue creating gay men's rituals around AIDS or our bodies - that's something I do a lot. Now I put the energy into [constructing] conscious and creative ritual space which is not built around this older model. I'm glad I have a relationship to it now as an artist and as a spiritual person, but I don't really want to kneel with the Nicene Creed or the structure of Christian worship services. I go a few times a year, but it's not central to my life.

Do you see the performance art sermon work as activism? Also, what kind of activism are you participating in now?

At this point, most of my activism is cultural, as an arts organizer and as a teacher. I think my activism has been most effective [responding to] gay men's hearts, feelings, and self-knowledge, so I think my workshops are probably where I was always the best activist anyway. Gathering gay men, proposing alternatives to how we can relate, creating different structures (performance spaces or workshops): within my limited energies this is the best place for me to be working. 